University of Windsor

Scholarship at UWindsor

2013

\title{
Collectivism and coping: Current theories, evidence, and measurements of collective coping
}

\author{
B.C.H Kuo \\ University of Windsor
}

Follow this and additional works at: https://scholar.uwindsor.ca/psychologypub

Part of the Psychology Commons

\section{Recommended Citation}

Kuo, B.C.H. (2013). Collectivism and coping: Current theories, evidence, and measurements of collective coping. International Journal of Psychology, 48 (3), 374-388.

https://scholar.uwindsor.ca/psychologypub/10

This Article is brought to you for free and open access by the Department of Psychology at Scholarship at UWindsor. It has been accepted for inclusion in Psychology Publications by an authorized administrator of Scholarship at UWindsor. For more information, please contact scholarship@uwindsor.ca. 
This article was downloaded by: [University of Windsor]

On: 16 February 2012, At: 06:40

Publisher: Psychology Press

Informa Ltd Registered in England and Wales Registered Number: 1072954 Registered office: Mortimer House, 37-41 Mortimer Street, London W1T 3J H, UK

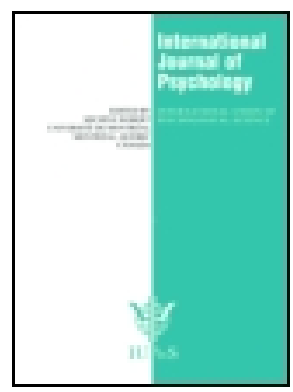

\section{International J ournal of Psychology}

Publication details, including instructions for authors and subscription information: http:// www.tandfonline.com/loi/ pijp20

\section{Collectivism and coping: Current theories, evidence, and measurements of collective coping}

Ben C. H. Kuo ${ }^{\text {a }}$

a Department of Psychology, University of Windsor, Windsor, Ontario, Canada

Available online: 16 Feb 2012

To cite this article: Ben C. H. Kuo (2012): Collectivism and coping: Current theories, evidence, and measurements of collective coping, International J ournal of Psychology, DOI:10.1080/ 00207594.2011.640681

To link to this article: http:// dx.doi.org/ 10.1080/00207594.2011.640681

\section{iFirst}

PLEASE SCROLL DOWN FOR ARTICLE

Full terms and conditions of use: http://www.tandfonline.com/page/terms-and-conditions

This article may be used for research, teaching, and private study purposes. Any substantial or systematic reproduction, redistribution, reselling, loan, sub-licensing, systematic supply, or distribution in any form to anyone is expressly forbidden.

The publisher does not give any warranty express or implied or make any representation that the contents will be complete or accurate or up to date. The accuracy of any instructions, formulae, and drug doses should be independently verified with primary sources. The publisher shall not be liable for any loss, actions, claims, proceedings, demand, or costs or damages whatsoever or howsoever caused arising directly or indirectly in connection with or arising out of the use of this material. 


\title{
Collectivism and coping: Current theories, evidence, and measurements of collective coping
}

\author{
Ben C. H. Kuo \\ Department of Psychology, University of Windsor, Windsor, Ontario, Canada
}

\begin{abstract}
$A$ burgeoning body of cultural coping research has begun to identify the prevalence and the functional importance of collective coping behaviors among culturally diverse populations in North America and internationally. These emerging findings are highly significant as they evidence culture's impacts on the stresscoping process via collectivistic values and orientation. They provide a critical counterpoint to the prevailing Western, individualistic stress and coping paradigm. However, current research and understanding about collective coping appear to be piecemeal and not well integrated. To address this issue, this review attempts to comprehensively survey, summarize, and evaluate existing research related to collective coping and its implications for coping research with culturally diverse populations from multiple domains. Specifically, this paper reviews relevant research and knowledge on collective coping in terms of: (a) operational definitions; (b) theories; (c) empirical evidence based on studies of specific cultural groups and broad cultural values/ dimensions; (d) measurements; and (e) implications for future cultural coping research. Overall, collective coping behaviors are conceived as a product of the communal/relational norms and values of a cultural group across studies. They also encompass a wide array of stress responses ranging from value-driven to interpersonally based to culturally conditioned emotional/cognitive to religion- and spirituality-grounded coping strategies. In addition, this review highlights: (a) the relevance and the potential of cultural coping theories to guide future collective coping research; (b) growing evidence for the prominence of collective coping behaviors particularly among Asian nationals, Asian Americans/Canadians and African Americans/Canadians; (c) preference for collective coping behaviors as a function of collectivism and interdependent cultural value and orientation; and (d) six cultural coping scales. This study brings to light the present theoretical and methodological contributions as well as limitations of this body of literature and the implications it holds for future coping research.
\end{abstract}

Keywords: Collective coping; Cultural coping; Cross-cultural coping; Multicultural coping; Collectivism.

$U$ ne quantité croissante d'études sur le coping culturel a commencé à identifier la prévalence et l'importance fonctionnelle des comportements de coping collectif parmi des populations culturellement diversifiées, tant en Amérique du Nord qu'ailleurs dans le monde. Ces nouvelles données sont grandement significatives puisqu'elles font ressortir les impacts de la culture sur le processus stress-coping à partir des valeurs et de l'orientation collectivistes. Elles fournissent un contrepoint critique au paradigme individualiste de stress et de coping prévalant en Occident. Cependant, la recherche et la compréhension actuelles concernant le coping collectif semblent manquer d'organisation systématique et d'intégration. Dans l'optique de mettre de l'ordre dans les données, cette revue tente d'inspecter, de résumer et d'évaluer globalement la recherche existante portant sur le coping collectif et ses implications pour les études réalisées auprès de populations culturellement diversifiées et dans des domaines multiples. Spécifiquement, cet article fait une recension des résultats de recherche et des connaissances pertinents portant sur le coping collectif en termes de: a) définitions opérationnelles; b) théories; c) preuves empiriques basées sur des études portant sur des groupes culturels spécifiques et sur des valeurs/ dimensions culturelles générales et d) mesures. Globalement, à travers les études, les comportements de coping collectif sont conçus comme un produit des normes et valeurs communautaires/relationnelles d'un groupe culturel. Ils contiennent aussi un large éventail de réponses face au stress, allant des stratégies de coping poussées par les valeurs, à celles qui sont basées sur des dimensions interpersonnelles, à celles qui sont conditionnées

Correspondence should be addressed to Ben C. H. Kuo, Department of Psychology, University of Windsor, 401 Sunset Ave., Chrysler Hall South, Windsor, Ontario, Canada, N9B 3P4. (E-mail: benkuo@uwindsor.ca).

(C) 2012 International Union of Psychological Science 
culturellement par des dimensions émotionnelles/cognitives, à celles qui sont ancrées dans la religion et la spiritualité. De plus, cette recension révèle: a) la pertinence et le potentiel des théories de coping culturel pour guider la recherche future sur le coping collectif; b) l'évidence grandissante de la proéminence des comportements de coping collectif, particulièrement parmi les nations asiatiques, les Américains/Canadiens Asiatiques et les Américains/Canadiens Africains; c) la préférence pour les comportements de coping collectif en tant que fonction du collectivisme et fonction des valeurs et de l'orientation culturelles interdépendantes et d) les six échelles de coping culturel. Le présent article met en lumière les contributions théoriques et méthodologiques actuelles tout comme les limites de ce champ d'étude et les implications pour la recherche future sur le coping.

$E$ 1 creciente cuerpo de investigación del afrontamiento cultural ha comenzado a identificar la prevalencia y la importancia funcional de las conductas de afrontamiento colectivo en poblaciones culturalmente diversas tanto en América del Norte como internacionalmente. Estos emergentes hallazgos son muy importantes, ya que evidencian el impacto de la cultura sobre el proceso de afrontamiento del estrés a través de la orientación y los valores colectivistas. Proveen un contrapunto crítico al paradigma vigente, occidental e individualista, del estrés y afrontamiento. Sin embargo, la investigación y entendimiento actual del afrontamiento colectivo parece estar fragmentado y no muy bien integrado. Para abordar esta problemática, esta reseña intenta estudiar, resumir y evaluar de manera exhaustiva las investigaciones existentes relacionadas con el afrontamiento colectiva y sus implicaciones para el estudio del afrontamiento en poblaciones culturalmente diversas de distintas áreas. Más específicamente, este artículo examina las investigaciones y el conocimiento relevante para el afrontamiento colectivo en términos de: a) definiciones operacionales, b) teorías; c) evidencia empírica basada en estudios de grupos culturales específicos y valores/dimensiones culturales generales y d) instrumentos de medición. En general, a través de los distintos estudios, las conductas de afrontamiento colectivo se conciben como un producto de normas relacionales y comunitarias y de los valores del grupo cultural. También abarcan una amplia gama de respuestas al estrés que van desde aquellas motivadas por los valores, las basadas en las relaciones interpersonales, las respuestas emocionales/cognitivas condicionadas culturalmente, hasta las estrategias de afrontamiento fundadas en la religión y la espiritualidad. Además, esta reseña destaca: a) la relevancia y el potencial del afrontamiento cultural en la dirección de las investigaciones futuras acerca del afrontamiento colectivo, b) la creciente evidencia de la preponderancia de las conductas de afrontamiento colectivo, especialmente entre ciudadanos asiáticos, estadounidenses o canadienses de origen asiático y afroamericanos o afrocanadienses, c) la preferencia por conductas de afrontamiento colectivo en función de la orientación y los valores culturales de colectivismo e interdependencia, y d) seis escalas de afrontamiento cultural. El presente artículo saca a relucir las contribuciones teóricas y metodológicas actuales, como así también las limitaciones de este cuerpo teórico y las implicaciones significativas que conlleva para el futuro de la investigación del afrontamiento.

The association between culture and coping was hypothesized as early as Lazarus and Folkman's (1984) seminal discussion on stress and coping. However, systematic reviews of cumulative research on culture and coping have been undertaken only recently (see Bhagat, Steverson, \& Kuo, 2009; Kuo, 2011; Wong \& Wong, 2006). These reviews have begun to identify: (a) cultural variability in coping preferences and patterns across national, racial, and ethnic groups and (b) the relationship between cultural specificity in coping and broad cultural dimensions, such as collectivism-individualism, interdependence-independence, and acculturation. One significant finding emerging from these syntheses of the cultural coping research is the eminence of coping behaviors that are deeply rooted in and derived from collectivistic values of culturally diverse populations, known as "collective coping" (Yeh, Arora, $\& \mathrm{Wu}, 2006)$.

Prevailing research has identified collective coping behaviors in studies of international, racially and ethnically diverse individuals, including Asian nationals (e.g., Heppner et al., 2006; Yeh, Inose, Kobori, \& Chang, 2001), Asian Americans/Canadians (e.g., Kuo, Roysircar, \& Newby-Clark, 2006; Yeh, Inman, Kim, \& Okubo, 2006), African Americans/Canadians (e.g., Joseph \& Kuo, 2009; Utsey, Adams, \& Bolden, 2000), and, to a lesser extent, Latino Americans (e.g., Chiang, Hunter, \& Yeh, 2004; Constantine, Alleyne, Caldwell, McRae, \& Suzuki, 2005). As a core component of coping repertoire, collective coping has also been found to hold implications for the physical and psychological wellbeing of culturally diverse individuals (Inman \& Yeh, 2007; Utsey, Adams, \& Bolden, 2000; Wester, Kuo, \& Vogel, 2006), and to be closely related to the religious identity of diverse groups (e.g., Muslims and Christians) (Fischer, Ai, Aydin, Frey, \& Haslam, 2010; Kuo et al., 2006). These emerging findings on culture-specific, collective coping behaviors are critical, as they stand in stark contrast to the dominance of culture-independent, 
intrapersonal, individualistic views of stress and coping in the extant coping literature (Folkman \& Moskowitz, 2004; Heppner, 2008).

Despite the evidence, current research and knowledge about collective coping behaviors are piecemeal and disjointed. At present few conceptual attempts (e.g., Chun, Moos, \& Cronkite, 2006; Yeh et al., 2006) have been made to expound the effects of collectivism on the stress-coping experiences of racially and ethnically diverse individuals. Consequently, the present knowledge base and research on cultural coping have been noted to be incomplete and culturally inadequate (Chun et al., 2006; Heppner, 2008; Inman \& Yeh, 2007). Hence, the present paper sets out to survey and present what we currently know about collective coping by summarizing and evaluating existing theories, empirical findings, and psychometric research.

\section{CONCEPTUAL CONTEXT FOR COLLECTIVISM AND COPING}

Collectivism and individualism are well-researched cultural constructs that have been linked broadly to the behavior, cognition, emotion, motivation and personality of groups and individuals (Hofstede, 2001; Markus \& Kitayama, 1991; Triandis, 2001). Coping, based on Lazarus and Folkman's classical definition, is construed as the "constantly changing cognitive and behavioral efforts to manage specific external and/or internal demands that are appraised as taxing or exceeding the resources of the person" (Lazarus \& Folkman, 1984, p. 141). Recently cultural coping scholars have contended that the theory of collectivismindividualism can help bolster our understanding of coping within a cultural context (Chun et al., 2006; Yeh et al., 2006), and better discern coping variations within and between cultures (Kuo, 2011). These observations find support in the emerging research on culture's relationship to social support (as a form of coping), suggesting that culturally prescribed interdependent vs. independent orientation can affect individuals' attitude to, selection of, context of, and outcome of (i.e., psychological, biological, and health) seeking support (Kim, Sherman, \& Taylor, 2008; Sherman, Kim, \& Taylor, 2009).

At a conceptual level the consideration of collectivism within the context of coping for culturally diverse populations is necessary for several reasons. First, the existing stress and coping research has been increasingly criticized for perpetuating a Western, European, individualistic worldview in its theories and research, as reflected in its limited focus on the intrapersonal and the agentic domains of coping (Dunahoo, Hobfoll, Monnier, Hulsizer \& Johnson, 1998; Heppner, 2008). This limitation is noticeable in the common emphasis placed on personal control, individual appraisal, and direct action by major theories of stress-coping (Folkman \& Moskowitz, 2004). Second, limited but growing evidence points to a strong cultural predisposition for group/otherdirected, collective coping among culturally diverse groups and individuals. For instance, recent works by Kuo and his colleagues have provided further evidence that cultural dimensions, such as collectivism-individualism and interdependence-independence, underpin cultural differences and specificities in coping patterns across cultures (Bhagat et al., 2009; Kuo, 2011; Kuo et al., 2006). Even though collective coping behaviors are also found among individualists, such as European Americans/Canadians (Kuo \& Gingrich, 2004), evidence suggests particularly that collective coping constitutes a core dimension of coping repertoire for individuals coming from more collectivistic cultural backgrounds (Utsey et al., 2000). Third, a scan of the existing cultural coping research suggests that for the most part the investigations of collective coping have been conducted and articulated by researchers working independently from each other, with limited exchange of ideas and findings among them. Hence, a deliberate effort to take account of and assimilate the existing understanding on collective coping into a more integrated body of knowledge is necessary and timely.

\section{THE PRESENT REVIEW}

The purpose of this paper is to review and evaluate evidence for collective coping in terms of: (a) operational definitions; (b) theories; (c) empirical evidence based on studies of specific cultural groups and broad cultural values/dimensions; (d) measurements of cultural and collective coping; and (e) implications for future cultural coping research. A thorough review of the literature was ensured by taking the following steps in order to identify published articles, book chapters, and dissertations in English pertaining to collective coping.

First, searches up to the year 2011 were conducted on key bibliographic databases, including PsycInfo, PsycArticles, and Social Sciences @ Scholars Portal, using the keywords "collective coping," "collectivistic coping," "collect* coping" and "collectivism and coping". The results yielded 
relatively little published research that explicitly dealt with collective coping defined in ways consistent with the present review - a cultural value-driven stress response acted upon by a person at the individual level. For instance, using the wildcard search term "collect* coping" on PsycInfo, a total of 15 publications (nine journal articles, three book chapters, and three dissertations) were identified after the removal of studies falling outside the inclusion criteria of this review. Second, the author of this review manually scanned the reference sections in the selected articles to identify additional published works on the subject. Finally, pertinent cultural coping research and literature falling outside of the above search methods but known to the author (e.g., conference papers and book chaptersapproximately 25 relevant published works) were also included.

It should be noted that research indirectly related to collectivism and coping, such as crosscultural studies on social support, is beyond the scope of the present review. This is because coping and social support are typically defined, measured, and examined as related but distinct constructs in the empirical research. Furthermore, as revealed by recent comprehensive reviews of the literature, research on culture and coping (Bhagat et al., 2009; Kuo, 2011) and on culture and social support (Kim et al., 2008; Sherman et al., 2009) constitute two complementary yet discrete bodies of knowledge, with substantial empirical studies associated with each. For these reasons, the present paper focuses mainly on published works specifically pertaining to collective coping, based primarily on cultural coping research.

\section{OPERATIONAL DEFINITIONS OF COLLECTIVE COPING}

In the existing literature, collective coping behaviors have been described with different terminologies by different researchers. For instance, the terms have included collectivistic coping style, collectivistic-oriented coping, communal coping, communalistic coping, socially oriented coping, other-focused coping, relational coping, family support coping, etc. For clarity and consistency, this review uses "collective coping" to denote coping behaviors derived specifically from collectivism value or orientation (Yeh et al., 2006; Zhang \& Long, 2006).

Similarly, the definitions of collective coping have varied across research. The divergence in the nomenclature and definitions appears to reflect the nascent nature of this area of research as well as a lack of assimilation of existing knowledge. Despite the absence of a unified definition, the prevailing depictions of collective coping converge on the emphasis of "cultural" and "social" motives and mechanisms underlying the stress and coping process. By definition "collectivism" is represented by individuals who are interdependent within their ingroup and regard the goals of the ingroup above their personal goals (Triandis, 2001). Collective coping distinguishes itself clearly from the individualistic, intrapersonally focused, and contextually independent European American view of coping in the extant coping literature (Heppner, 2008; Moos, 2002). Functionally speaking, collective coping efforts are intended to: (a) engage others in meaningful, purposeful, and culturally congruent ways, and (b) give consideration to the wellbeing of important others during the process of coping (Moore \& Constantine, 2005). More specifically, the actual collective coping behaviors reported in the existing literature encompass a wide array of coping responses. They have included: (a) coping strategies grounded in the values of forbearance, fatalism, familism, and honoring authority figures; (b) interpersonally based coping methods through a reliance on ingroup interdependence, such as seeking family support and social support from coethnic members; (c) culturally shaped emotional and cognitive coping strategies, such as acceptance, reframing, detachment, avoidance, and focusing on the positive; and (d) coping behaviors stemming from beliefs and practices of culturally specific religion, spirituality, and ritual (Fischer et al., 2010; Heppner et al., 2006; Kuo et al., 2006; Utsey et al., 2000; Yeh et al., 2003). On the basis of these characteristics, collective coping is conceptually defined as a broader construct than "social support" in the literature (e.g., Kim et al., 2008). In sum, collective coping behaviors are being conceptualized as a constellation of multifaceted stress responses shaped and enhanced by collectivistic norms, values, and tendencies.

\section{THEORIES OF COLLECTIVE COPING}

Currently very few stress-coping theories have incorporated the influences of cultural values, such as collectivism or individualism, into the understanding of stress and coping processes. This review identified three cultural stress-coping theories most relevant to the discussion of collective coping. They are reviewed and discussed below. 


\section{Conservation of resources theory of stress and coping}

Taking an anthropological perspective, Hobfoll's conservation of resources theory (COR; Hobfoll, 1998, 2001) assumes a social, collective framework in viewing individuals' stress-coping experiences. Hobfoll stipulated that stress is a product of individuals' need to ensure the survival of the species and to fend off potential threats to the survival of the self, family, or tribe (Dunahoo et al., 1998; Hobfoll, 1998, 2001). A person's coping, as a stress response, must be understood within the frame of "individual in social context" and be viewed as a function of one's family, neighborhood, religion, employment, charitable organizations, ethnic ingroup, etc. The COR theory classifies coping broadly in terms of individualistic vs. socially oriented coping. While in Hobfoll's original theory the term "collective coping" was not used, collective coping behaviors align conceptually with the socially oriented coping category.

Within this framework, collective coping is effectively characterized by stress responses that are motivated by social goals, such as the preservation of ingroup others' wellbeing and interpersonal harmony. However, as noted by Hobfoll (2001) himself, the COR theory delineates a "broad-based motivational theory" based on the general stress process. Accordingly, Hobfoll does not regard the COR as a theory of "prediction," as he argues that it "loses fidelity on the microanalytical level" (Hobfoll, 2001, p. 361). Therefore, while the COR is conceptually enlightening and culturally informative, it is less appropriate for research interested in the interactive relationships (or transactions) among various components of stress responses at the microprocess level.

\section{Sociocultural model of stress-coping- adaptation}

According to Aldwin's (2007) sociocultural model of coping, the stress-coping process is constructed within an individual's social context, which in turn is deeply entrenched in the individual's cultural context. Aldwin contended that culture's influences pervade the entirety of the process of stress and coping. Consequently, the theory predicts that individuals' culture is likely to dictate: (a) the kind of stressors typically faced; (b) the degree of perceived stressfulness and significance of a certain stressor; (c) the selection and preference for particular types of coping strategy in dealing with a given stressor; and (d) typical institutional resources and mechanisms from which people seek help in order to cope with stress, such as community services, interpersonal support, or psychotherapy.

The sociocultural theory posits that an individual's larger cultural beliefs and values, the person's own beliefs and values, the situational demand of the stressor, and the cultural demands and resources converge to shape the person's subsequent stress and coping responses (Aldwin, 2007). Specifically, at the microprocess level the theory asserts that a person's coping decision is a product of his/her perceived reaction from others, appraisal of stress, coping resources, social support, and coping efforts. Furthermore, individuals' experiences with cultural expectations (e.g., collective rules and norms) and resources would determine how they evaluate and appraise the demand of a given stressful event and the means and resources available to them to cope in the face of that stressor. Finally, the abovementioned factors are hypothesized to affect the social support and the coping efforts of the individual, which in turn lead to the eventual outcomes of coping manifested through cultural, social, situational, psychological, and physiological effects. This last point is corroborated by recent research findings on culture's effects on social support (see Sherman et al., 2009 for a more in-depth review). Overall, the sociocultural theory appears to be conceptually useful to help comprehend the potential influences of cultural beliefs/values, such as collectivism, on the process of coping because the components of the model are relatively well specified. However, the validity of the theory awaits further empirical verification.

\section{Cultural transactional theory of stress and coping}

The cultural transactional theory of stress and coping proposed by Chun et al. (2006) attempts to address the direct and indirect links between collectivism-individualism and stress-coping. The theory is unique in describing critical components of the coping process and hypothesizing various behavioral and psychosocial consequences of these elements that are born out of collectivistic vs. individualistic values. The model is presented in Figure 1. The authors assert that culture acts on the entire stress-coping process by way of collectivistic or individualistic value influences across five sequential panels (see Figure 1). 


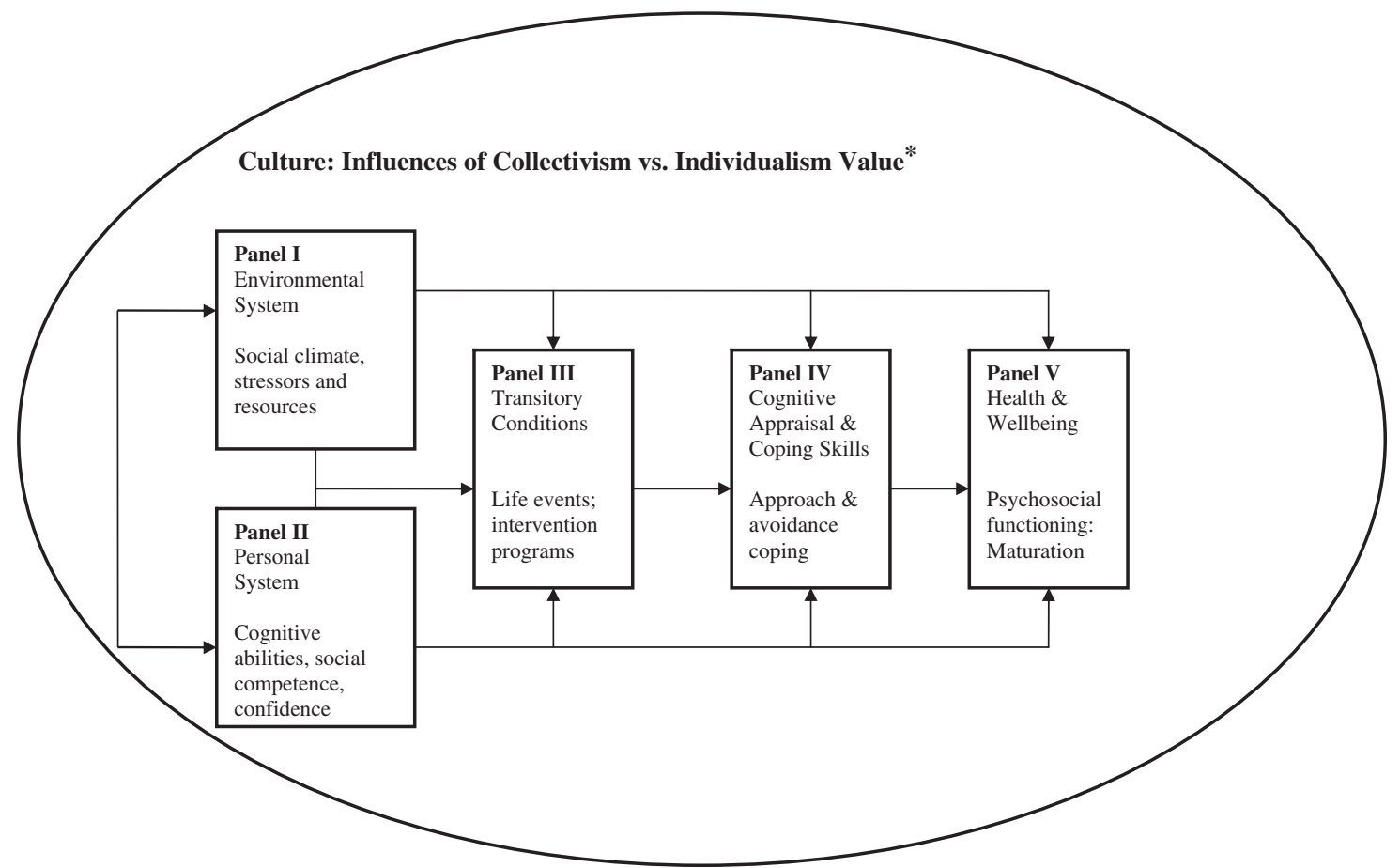

Figure 1. The cultural transactional theory of stress and coping as proposed by Chun, Moos, and Cronkite (2006). In P. T. P Wong and L. C. J. Wong (Eds.), Handbook of Multicultural perspectives on stress and coping (p. 30). New York, NY: Springer. Copyright 2006 by Springer Science-Business Media, Inc. Adapted with permission. *Information supplemented based on the original theory.

For Panel I, environmental system, the theory predicts that stress and coping are likely to center around issues of personal autonomy and independence for individualists, and around issues of one's social obligations and responsibilities to one's family and ingroups for collectivists. Also, the social support systems for individualists are said to include loosely connected members in a small number of social groups, such as immediate families and friends. For collectivists, the social networks are said to consist of tightly connected members across a large number of social groups, including immediate and extended families, kin, and friends. For Panel II, personal system, the theorists observed that members of independent (individualistic) cultures are likely to favor internal locus of control due to the predisposition towards self-reliance and personal independence and mastery. Members of interdependent (collectivistic) cultures are likely to favor external locus of control in evaluating stressors and in enlisting coping strategies because of the tendency to believe in forces residing outside oneself, such as supernatural power or power embedded in the social hierarchy.

Under Panel III, transitory conditions, the model stipulates that individualists would perceive events disrupting one's independence and selfdevelopment to be more threatening and stressful than would collectivists. In contrast, collectivists would perceive disruption to one's interdependence, social harmony, security, and sense of consistency to be more threatening and stressful than would individualists. In this respect, cultural values serve to delimit what are typical/normative vs. atypical stressors, and subsequently determine the valence of these stressors for members of a cultural group (Chun et al., 2006). For Panel IV, cognitive appraisal and coping skills, the model differentiates between primary vs. secondary control coping (Weisz, Rothbaum, \& Blackburn, 1984). Chun et al. (2006) hypothesized that coping methods aimed at confronting and modifying external stressors (i.e., primary control), such as behavioral, problem-focused, or approachoriented coping, would be more prevalent in individualistic cultures. This behavioral pattern is attributable to individualists' emphasis on personal autonomy and the mastery of the environment (Lam \& Zane, 2004). Coping strategies aimed at modifying oneself (i.e., secondary control), such as cognitive avoidance or emotion-focused coping, would be more common in collectivistic cultures. This is due to collectivists' emphasis on social dependence and harmony (e.g., not "rocking the boat") (Lam \& Zane, 2004). Furthermore, under this panel Chun et al. (2006) underscored collective coping as a distinctive form of stress responses 
practiced by collectivists because of their tendency to seek support from their ingroups, and to reinforce "interconnectedness with the ingroup" (Chun et al., p. 43) through such behaviors.

Finally, Panel V, health and wellbeing, posits that culture can also shape the eventual outcomes of coping, which in turn bear implications for physical and emotional wellbeing at the individual level. For individualists, coping outcome is typically defined and measured by the reduction of stress or distress, as is typically done in the extant coping and psychological research. However, it is posited that for collectivists coping effectiveness might additionally be appraised in terms of social and relational consequences (e.g., preserving ingroup harmony, fulfilling social obligations, enhancing mutual interdependence).

In summary, both the cultural transactional theory and the sociocultural theory are comprehensive, process-oriented cultural models of stress and coping that hold the potential to be used in studying culture's impact on coping at the microanalytical level. However, to the author's knowledge, no research to date has empirically tested either of these cultural coping theories. For heuristic purposes a deliberate effort is made in this paper to apply and to map the cultural transactional theory onto collective coping research reviewed in the subsequent sections. The transactional theory is chosen because the model is succinct and intuitive, and is composed of relatively well-defined panels and factors related to coping. The hope is that such a conceptual framework can help situate, organize, and interpret an otherwise unassimilated body of empirical knowledge on collective coping.

\section{EMPIRICAL RESEARCH EVIDENCE FOR COLLECTIVE COPING}

Panel IV, cognitive appraisal and coping, of the cultural transactional theory (Figure 1) stipulates that the predominant values of a cultural group are likely to predispose members of that group to certain coping patterns and preferences. Logically, one would expect to see that cultures favoring collectivism would likely predispose their members towards collective coping behaviors. With this in mind, this paper now reviews empirical research that investigated: (a) collective coping strategies among racial and ethnic individuals and international samples; and (b) collective coping's direct relationship to the cultural dimensions of collectivism and interdependence. The published works identified for this review are dominated by research with Asians, Asian Americans Canadians, and African Americans/Canadians. The searches failed to identity a substantial number of collective coping studies for other cultural groups (e.g., Latinos/Latinas) to allow for a comprehensive analysis. Thus, the following discussion focuses only on available empirical research with the three abovementioned cultural groups.

\section{Collective coping among Asians and Asian Americans/Canadians/Australians}

Consistent with strong collectivistic values and norms found in Asian cultures (Inman \& Yeh, 2007; Markus \& Kitayama, 1991), collective coping behaviors have been identified in cultural coping research with Asian nationals as well as Asian immigrants typically in the US and Canada. In an early psychometric study of a Chinese indigenous coping scale, the Chinese Coping Scale, Shek and Cheung (1990) found two major coping factors associated with the scale based on a sample of Chinese working parents in Hong Kong. These coping factors were: (a) internal "reliance on the self" coping and (b) external "seeking help from others" coping. The latter factor reflected collective coping represented by soliciting help from spouse, friends, parents, in-laws, relatives, supervisors, professionals, and even fortune-tellers. In a more recent study, Yeh and Wang (2000) found that in response to mental health problems, Asian American college students relied heavily on familial and social sources for coping support. These participants identified engagement in family activities and social activities with friends and peers as primary means of coping in dealing with psychological problems. These findings support Panel I, environmental system, of the cultural transactional model, which predicts the coping support systems for collectivists to be represented by larger, multiple social groups as shown in the preceding studies.

Furthermore, Yeh et al. (2006) conducted qualitative interviews with 11 Asian American family members of the victims of the World Trade Center terrorist attack to study their coping. The study revealed that six of the eight primary coping methods reported by these participants were culture-specific, collectivistic strategies: familial coping, intracultural coping, relational universality, forbearance, fatalism, and indigenous healing, all of which reflect deep-seated Asian collectivistic values and practices. Wei, Heppner, $\mathrm{Ku}$, and Liao's (2010) recent study found that collective 
coping in the form of family support moderated the association between racial discrimination, stress, and depression for Asian American college students. The investigators concluded that collective coping through acquiring guidance and support within a collectivistic family environment can serve to protect Asian Americans against the adverse impacts of racism.

Also, there is additional evidence suggesting that predisposition toward collective coping is socialized early among Asian adolescents and children. Neill and Proeve (2000) found that Southeast Asian adolescent students in Australia reported a greater use of "reference to others" (i.e., collective coping) as coping than European Australian high school adolescents. In another comparative study, McCarty et al. (1999) found that in dealing with hypothetical social situations (e.g., involving doctor and parents), Thai children (ages 6-14 years) were twice as likely as American children to report covert coping, i.e., inwardly directed, emotion-focused responses. The use of covert coping by Thai children was said to be motivated by the strong collective and interdependent norms of the Thai culture, as it served to preserve social harmony with important others.

However, recent empirical works have revealed nuanced effects of social support, as a form of collective coping, on Asian American samples depending on the type of social support being sought (Kim et al., 2008). For instance, in an experimental study, Taylor, Welch, Kim and Sherman (2007) found that "implicit social support" was psychologically (i.e., based on selfreport stress levels) and biologically (i.e., based on level of cortisol) more beneficial for Asian and Asian American college students, while "explicit social support" was less beneficial for the same group, in comparison with European American college students. These researchers defined implicit social support as "the emotional comfort one can obtain from a social network without disclosing or discussing one's problem vis-à-vis a specific stressful event" (Taylor et al., 2007, p. 832). This form of coping stands in contrast to "explicit social support," which involves directly drawing advice, aid, and emotional comfort from one's social networks. The former affords individuals of collective background a sense of solace and emotional comfort through their being aware of the existence of their social groups without burdening them with actual demands. Researchers in this area attribute the benefit of implicit social support to the emphasis on relational and social contexts of coping among Asians and Asian Americans due to collective and interdependent cultural predispositions (Sherman et al., 2009; Taylor et al., 2007).

This social context-dependent perspective on coping speaks to the transaction between Panels III and IV of the cultural transaction theory (Figure 1). That is, for collectivists the significance associated with a stressor is typically appraised based on one's collective and relational norm (Panel III), and the subsequent coping responses evoked are regulated in accordance with such an assessment (Panel IV).

\section{Collective coping among African Americans/Canadians}

Evidence of collective coping behaviors has also been revealed in coping studies with individuals of African descent in the US and Canada. Conceptually, Utsey and his colleagues hypothesized that the stress and coping response of African Americans is distinctly characterized by an "Africentric" perspective of coping deeply rooted in culturally specific (emic), communal, and spiritual coping strategies (Utsey et al., 2000). Constantine, Donnelly, and Myers (2002) investigated the relationship between collective selfesteem and culture-specific coping among 106 African American high schoolers. The study found that African American youth who reported a stronger public collective self-esteem (believing that others perceive African Americans as positive) were more likely to engage in the use of spiritualcentered Africultural coping strategies. On the other hand, African American youth who reported a higher importance to identity collective selfesteem (believing that being African American is an important part of their self-concept) were more likely to engage in the use of collective coping. The study exemplifies the critical role of the personal system (Panel II) of the cultural transactional theory-in this case the role of collective selfesteem in predicting coping preferences among African American youth.

In a Canadian study, Joseph and Kuo (2009) examined Black Canadians' coping responses with three racial discrimination situations (interpersonal, cultural, and institutional). The study found that Black Canadians adopted a mixture of both Africultural and conventional coping strategies (e.g., problem- and emotion-focused coping) in dealing with discrimination in a context-dependent fashion. For example, the participants responded to interpersonal discrimination with culturally based coping strategies in the following order of preference: spiritual- 
centered, ritual-centered, collective, and cognitive/ emotional debriefing. These cultural coping strategies were also found to be important in Black Canadians' coping with institutional and cultural discrimination situations, along with the use of problem-solving strategies. Similarly, Lewis-Coles and Constantine (2006) revealed that African American women who perceived greater stress related to institutional racism were more likely to endorse collective coping strategies along with cognitive/emotional debriefing coping and spiritual-centered coping to deal with their difficulties. On the other hand, African American men who perceived greater stress associated with cultural discrimination were more likely to use collective coping strategies to manage the situation. Gaylord-Harden and Cunningham (2009) studied coping with racial discrimination in a sample of low-income African American early adolescents (6th to 8th grades). The study revealed that African American youth who reported high levels of discrimination utilized more collective coping (i.e., communalistic coping), spiritual coping, and emotional debriefing. The use of collective coping was also found to be predictive of fewer depressive symptoms for these adolescents when discrimination-related stress was not severe. These findings point to collective coping as a central coping mechanism in mitigating race-related stressors for individuals of African descent.

Taken together, these preliminary results suggest that collectivism and Africentric values underpin the adaptation and coping process among African Americans/Canadians. In addition, collective coping might well mediate or moderate the stress-health outcome relationship for this population across a wide variety of stressors. These results provide some support for the transactional coping pathway going from Panel I (stressor) to Panel IV (collective coping) to Panel V (health and wellbeing) according to the cultural transactional theory (Figure 1).

\section{Collective coping and interdependent self construal}

In addition to group-specific research on collective coping behaviors, studies assessing the direct association between collective/interdependent values and coping have provided further evidence that cultural difference and specificity in coping preferences can vary along the specific cultural dimensions of collectivism-individualism and interdependence-independence (Kuo, 2011). Using path analysis, Cross (1995) assessed the influence of interdependent-independent self-construals on coping. East Asian students' level of independence was found to be positively related to the use of direct actions or planning to cope with cultural adjustment. Yeh et al. (2001) assessed native Japanese students' collective identity in relation to their coping preferences. Collective identity was defined and measured in terms of the degree of importance of family, ethnic group, community, religion, and language to an individual. Higher levels of collective identity among Japanese predicted a greater preference for collective coping strategies through soliciting assistance from family, siblings, and friendship network. These findings are significant because they empirically link individual-level collectivism/interdependence to the preference for collective and communalistic coping methods.

Adopting a control-based model of coping, Lam and Zane (2004) tested the mediating effect of selfconstruals on ethnicity and preference for primary (i.e., change circumstance externally) versus secondary (i.e., change oneself internally) control coping strategies. The study revealed that when facing interpersonal stress, Asian American college students were more likely to cope by modifying their thoughts and feelings in order to accommodate external stressors (secondary control). This tendency was attributed to the strong sense of collectivism, familism, and social connectedness among Asian Americans. On the other hand, White American college students reported that they preferred changing the environment or the external stressor to fit their own needs (primary control). This predilection was attributed to Western individualism's emphasis on autonomy, self-determiniation, and mastery of the environment (Markus \& Kitayama, 1991).

In yet another study, Kuo and Gingrich (2004) found differential effects of self-construals on Asian and Caucasian Canadian university students' preferences for collective, avoidance, and engagement coping. Irrespective of the participants' ethnicity, interdependence (i.e., more collective) was positively predicted by the use of all three types of coping method, whereas independence (i.e., more individualistic) was positively predicted by only engagement coping. More interdependent respondents also rated the hypothetical interpersonal conflict scenario presented in the study to be more stressful than their less interdependent counterparts. These findings suggest that culturally prescribed interdependence or collectivism not only dictates a person's coping preference but also determines the person's appraisal of stressors in certain predictable ways. 
In short, the findings above highlight that collectivists typically hold secondary-controlled coping goals comprising efforts to change oneself, at the same time as they use coping methods that involve sociocultural ingroups as support, resources, and reference points (e.g., collective coping), emotion-focused coping, and avoidance coping (Kuo et al., 2006). In contrast, individualists typically hold primary-controlled coping goals with efforts to modify the stressor/external condition, while they tend to utilize coping methods that involve individual-based, active, problem-solving strategies (Kuo, 2011).

\section{MEASUREMENTS OF COLLECTIVE COPING}

Another source of empirical evidence for collective coping behaviors stems from psychometric studies of culturally based coping measures. A review of the cultural coping literature identified six such emic (culture-specific) coping measures published in English. They include: (a) the Africultural Coping Systems Inventory by Utsey et al. (2000); (b) the Collectivistic Coping Scale by Yeh et al. (2003); (c) the Collectivistic Coping Styles Measure by Moore and Constantine (2005); (d) the Collective Coping Styles Inventory by Heppner et al. (2006); (e) the Cross-Cultural Coping Scale by Kuo et al. (2006); and the Collective Coping Scale by Zhang and Long (2006). Table 1 provides an overview of these coping scales and their corresponding psychometric information. A detailed review of these measures is beyond the scope of the current paper. Readers are referred to the original studies of these measures for more in-depth information and examination.

However, as reported in these psychometric studies, all six measures are grounded in the assumptions of collectivism and the indigenous practices of stress responses among culturally diverse samples. Accordingly, all of these scales implicate collective coping or collectivism in the name of either these scales or of their subscales. As shown in Table 1, these culturally based coping measures were developed and tested with diverse samples of differing national, racial, ethnic, and developmental backgrounds. Based on the initial psychometric information reported by the various scale developers, the initial validity and the reliability indicators for these measures appear promising.

Overall, the structure and the psychometrics of these six emically-derived cultural coping measures provide a further nuanced and fine-grained analysis of cultural coping by highlighting the distinctive domains and characteristics of collective coping. For example, the Collectivist Coping Styles Inventory developed by Heppner and his colleagues conceptualizes and assesses collective coping in terms of five subscales: (a) Acceptance, Reframing, and Striving; (b) Family Support; (c) Religious/Spirituality; (d) Avoidance and Detachment; and (e) Private Emotional Outlets (Heppner et al., 2006). According to the developers of the measure, these dimensions reflect broad Asian collectivistic values and philosophies and the primary and secondary control tendencies of Taiwanese nationals, the sample on which the scale was developed.

As a whole, the advent of these measures represents a significant step forward to counterbalance the individualistic and "acontextual" biases in the conventional measurement approach used to assess coping. While this development is highly encouraging, a review of the literature also showed that only four studies were published in the past five years (Horn, 2008; Joseph \& Kuo, 2009; Kim, 2009; Wei et al., 2010) based on any of these six cultural coping measures. Clearly, more extensive research to discern the validity, the utility, and the generalizability of these coping measures is needed.

\section{DISCUSSION}

This review sets out to comprehensively take stock and to synthesize what we currently know about collective coping based on theoretical, empirical, and psychometric evidence and research. From this standpoint, it bridges a significant gap in the current individualism-dominated coping literature by providing insights into the ways in which collective coping behaviors are conceptualized, defined, and assessed. In addition, this review sheds light on the types and forms, the purposes and goals, and the adaptive functions of collective coping from a culturally informed and crosscultural perspective. Key findings are as follows.

First, conceptually, collective coping has been defined as a set of coping responses born out of the collective and relational norms of a cultural group or an individual (Heppner et al., 2006). Functionally, collective coping is found to enable an individual to enlist the assistance of ingroup others in a way that maintains sensitivity towards the wellbeing of those others (Moore \& Constantine, 2005). In terms of its form and substance, collective coping encompasses a broad spectrum of stress responses ranging from valuedriven strategies (e.g., forbearance and fatalism) to 
TABLE 1

Profiles and characteristics of six culturally based coping measures

\begin{tabular}{|c|c|c|c|}
\hline Measure & $\begin{array}{c}\text { Instrument development studies } \\
\& \text { samples }\end{array}$ & $\begin{array}{c}\text { Factors/Subscale (no. of items: } \\
\text { alpha) }\end{array}$ & $\begin{array}{l}\text { Sociocultural validity } \\
\text { estimates }^{a}\end{array}$ \\
\hline $\begin{array}{l}\text { Africultural Coping } \\
\text { Systems Inventory } \\
\text { (Utsey et al., 2000) }\end{array}$ & $\begin{array}{l}\text { Content Validity Test: } 7 \\
\text { African Americans \& } \\
\text { Afro-Caribbeans } \\
\text { Pilot: } 72 \text { African Americans } \\
\text { EFA: } 180 \text { African Americans } \\
\text { CFA: } 220 \text { African Americans }\end{array}$ & $\begin{array}{l}\text { Collective coping } \\
\quad(8: \alpha=.71-.78) \\
\text { Spiritual-centered coping } \\
\quad(8: \alpha=.79-.82) \\
\text { Ritual-centered coping } \\
\quad(3: \alpha=.75-.76) \\
\text { Cognitive/Emotional } \\
\quad \text { debriefing } \\
\quad(11: \alpha=.79-.80)\end{array}$ & None reported \\
\hline $\begin{array}{l}\text { Collectivistic Coping Scale } \\
\text { (Yeh et al., 2003) }\end{array}$ & $\begin{array}{l}\text { Pilot: } 35 \text { Americans } \\
\text { EFA \& Reliability: } 504 \text { diverse } \\
\text { ethnic Americans } \\
\text { CFA: } 463 \text { Mixed ethnic } \\
\text { Americans } \\
\text { Test-Retest } R \text { : } 40 \text { diverse ethnic } \\
\text { Americans } \\
\text { Convergent } V \& \text { Discriminant } \\
V: 225 \text { diverse ethnic } \\
\text { Americans }\end{array}$ & $\begin{array}{l}\text { Respect for authority } \\
\quad \text { figures }(5: \alpha=.93) \\
\text { Forbearance }(5: \alpha=.89) \\
\text { Social activity }(5: \alpha=.90) \\
\text { Intracultural coping }(5: \alpha=.94) \\
\text { Relational universality } \\
\quad(6: \alpha=.91) \\
\text { Family support }(5: \alpha=.80) \\
\text { Fatalism }(5: \alpha=.88)\end{array}$ & $\begin{array}{l}\text { Individualism- } \\
\quad \text { collectivism } \\
\text { Collective self-esteem } \\
\text { Differential of self } \\
\text { Social support }\end{array}$ \\
\hline $\begin{array}{l}\text { Collectivistic Coping } \\
\text { Style Measure (Moore } \\
\text { \& Constantine, 2005) }\end{array}$ & $\begin{array}{l}\text { CFA, Convergent, } \\
\text { Discriminant, Concurrent } V \text {, } \\
\text { \& Test-Retest } R: 204 \\
\text { African, Asian, Latino, } \\
\text { international students in US }\end{array}$ & $\begin{array}{l}\text { Seeking social support } \\
\quad(5: \alpha=.84) \\
\text { Forbearance }(4: \alpha=.95)\end{array}$ & $\begin{array}{l}\text { Self-construals } \\
\text { Social support } \\
\text { Interpersonal harmony } \\
\text { Psychological help- } \\
\quad \text { seeking }\end{array}$ \\
\hline $\begin{array}{l}\text { Collectivist Coping } \\
\text { Styles Inventory - } \\
\text { Heppner et al. (2006) }\end{array}$ & $\begin{array}{l}\text { Pilot: } 3 \text { Asian Americans \& } \\
2 \text { European Americans } \\
\text { EFA: } 344 \text { Taiwanese nationals } \\
\text { CFA \& Concurrent \& } \\
\text { Construct } V: 2889 \\
\text { Taiwanese nationals } \\
\text { Discriminant } V \& \text { Test-Retest } \\
R: 38 \text { Taiwanese } \\
\text { nationals }\end{array}$ & $\begin{array}{l}\text { Acceptance, reframing, } \& \\
\quad \text { striving } \\
\quad(11: \alpha=.82-.87) \\
\text { Family support }(6: \alpha=.86-.87) \\
\text { Religious/Spirituality } \\
\quad(4: \alpha=.88-.90) \\
\text { Avoidance } \& \text { Detachment } \\
\quad(5: \alpha=.60-.77) \\
\text { Private emotional outlets } \\
\quad(4: \alpha=.60-.76)\end{array}$ & $\begin{array}{l}\text { Trauma interference } \\
\text { Problem resolution } \\
\text { PTSD diagnosis } \\
\text { Problem-solving style } \\
\text { Social desirability }\end{array}$ \\
\hline $\begin{array}{l}\text { Cross-Cultural Coping } \\
\text { Scale (Kuo et al., 2006) }\end{array}$ & $\begin{array}{l}\text { Pilot: } 7 \text { Chinese American } \\
\text { adolescents } \\
\text { EFA: } 284 \text { Chinese Canadian } \\
\text { adolescents } \\
\text { CFA \& Criterion V.: } 174 \text { Asian } \\
\text { Canadians \& European } \\
\text { Canadians } \\
\text { Concurrent V. \& Test-Retest } \\
R: 375 \text { Asian \& Middle } \\
\text { Eastern international stu- } \\
\text { dents in US }\end{array}$ & $\begin{array}{l}\text { Collective coping } \\
\quad(8: \alpha=.74-.80) \\
\text { Engagement coping } \\
\quad(5: \alpha=.52-.65) \\
\text { Avoidance Coping } \\
\quad(7: \alpha=.63-77)\end{array}$ & $\begin{array}{l}\text { Acculturation } \\
\text { Self-construals } \\
\text { Religiosity }\end{array}$ \\
\hline $\begin{array}{l}\text { Collective Coping Scale } \\
\text { (Zhang \& Long, 2006) }\end{array}$ & $\begin{array}{l}\text { Focus group: } 20 \text { Chinese pro- } \\
\text { fessionals in US \& Canada } \\
\text { EFA, Convergent } V, \& \\
\text { Predictive } V: 228 \text { overseas } \\
\text { Chinese professionals }\end{array}$ & $\begin{array}{l}\text { Collective coping }(13: \alpha=.90) \\
\text { Engagement coping }(11: \\
\quad \alpha=.78) \\
\text { Disengagement coping }(9: \\
\quad \alpha=.70)\end{array}$ & $\begin{array}{l}\text { Chinese cultural values } \\
\text { Self-efficacy } \\
\text { Social support } \\
\text { Work support }\end{array}$ \\
\hline
\end{tabular}

EFA = exploratory factor analysis; CFA = confirmatory factory analysis. ${ }^{\mathrm{a}}$ For brevity, nonsociocultural variables (e.g., symptom or other coping measures) are not listed. ${ }^{\mathrm{b}}$ This scale was designed specifically for coping within work contexts.

interpersonally-based strategies (e.g., family and social support), to culturally conditioned emotional/cognitive strategies (e.g., acceptance and avoidance) to religion- and spirituality- grounded strategies (Fischer et al., 2010; Kuo et al., 2006). In general, these elements of collective coping are reflected in the design and the structure (i.e., items and factors) of the six cultural coping measures 
reviewed in this paper, and are consistent with the assumption of the cultural transaction theory (e.g., Panel IV in Figure 1).

Second, the findings of this review corroborate the predictions of cultural coping theories (e.g., Chun et al., 2006; Yeh et al., 2006) by offering evidence of prevalence and prominence of collective coping among groups and individuals associated with collectivistic cultural backgrounds. As demonstrated in this paper, there is growing evidence across studies pointing to the salience of collective coping patterns among Asian nationals, Asian Americans/Canadians, and African Americans/Canadians. In particular, collective coping strategies have been found to be especially relevant for racial and ethnic individuals when facing interpersonal and relational stressors that involve significant others (Kuo \& Gingrich, 2004; McCarty et al., 1999).

Third, this article has identified initial empirical evidence that links collectivistic cultural values to coping behaviors. Specifically, the results show that cultural variability in coping preferences can vary along broad, empirically validated dimensions of culture, such as collectivism and individualism. These observations represent a critical step forward in cultural coping research, because they suggest that cultural differences and specificities in coping can now be quantitatively "unpackaged," assessed, and explained through meaningful measures of cultural constructs, including interdependent-independent self-construals (e.g., Cross, 1995; Kuo \& Gingrich, 2004) and collective identity (e.g., Constantine et al., 2002; Yeh et al., 2001). These findings should afford researchers greater confidence in conceptualizing and interpreting research findings with culturally diverse participants based on validated a priori crosscultural theories and/or empirically validated cultural variables.

\section{Limitations}

The preceding observations should be considered with caution in view of the following limitations and caveats. First, as pointed out in the earlier sections of this paper, collective coping research is clearly in its infancy. While empirical research on collective coping behaviors is deemed to be timely and much needed (Fischer et al., 2010; Wong \& Wong, 2006), this continues to be an understudied area within cultural and crosscultural coping research. To enable more in-depth evaluation and synthesis of this body of knowledge in the future, a concerted effort to promote and build a critical mass of empirical studies on collective coping is imperative.

Second, the present review reveals a lack of convergence among the existing research on collective coping. For instance, there is no evidence that the available theories, empirical studies, and measurement research are being integrated or assimilated in any systematic and cohesive manner. There remains a heavy reliance on crosscultural psychological literature unrelated to coping and/or anecdotal observations by the researchers within the existing collective coping studies (Kuo, 2011). Furthermore, while important findings have emerged from the collective coping studies reviewed, the development of this corpus of research has been sporadic and slow. The resultant impact is observable in the divergent ways in which collective coping has been termed, operationalized, and assessed across studies and researchers, as noted earlier.

Third, the corpus of empirical research on collective coping established thus far has been dominated by studies with samples of Asians, Asian Americans/Canadians and African Americans/Canadians. Therefore, very limited knowledge is currently available about collective coping behaviors among other racial/ethnic minority and international groups, such as Latinos/ Latinas, Native Americans, Pacific Islanders, and Muslims. Hence, the generalizability to other cultural groups of the findings identified in this review can only be speculative.

\section{Implications for research}

On the basis of the present review, a number of recommendations for future research are made. First, more systematic formulation and articulation of cultural coping theories, grounded in the principles of collectivism-individualism and interdependence-independence and the emerging cultural coping research, are needed (Heppner, 2008; Wong \& Wong, 2006). As a starting point, coping researchers may consider incorporating, testing, and refining any of the three cultural coping theories reviewed here in coping studies with diverse immigrants, racial/ethnic minorities, and international populations. Adopting a consistent cultural theory over time would render cultural coping research findings and data across studies more comparable and interpretable in a long run. A theory-guided approach would also enable researchers to pinpoint relevant environmental and psychosocial factors (e.g., panels/systems) as well as gaps in the process of coping for research 
purposes. For instance, the cumulative cultural coping research thus far appears to have focused primarily on identifying and delineating collective coping and assessing its efficacy (i.e., reduction of stress) - that is, issues concerned mainly with the elements of Panels IV and V of the cultural transactional model (see Figure 1). More research efforts are needed to shed light on the other, underresearched components of the model, including the environmental, the personal, and the transitory conditions and stressors.

Second, it is recommended that future cultural coping research consider adopting cultural coping measures highlighted in this paper. These emic cultural coping instruments can be implemented either in conjunction with or in place of more general coping measures (Ways of Coping Questionnaire, COPE, etc.). As an alternative, an etic-emic integrated approach was attempted in a number of previous coping studies, such as the coping study with Black Canadians by Joseph and Kuo (2009) and the comparative study of Japanese, Asian Canadians, and European Canadians by Tweed, White, and Lehman (2004). This integrated approach incorporates both conventional coping (etic) and culture-specific coping items/scales (emic) in the study and allows researchers to sample participants' coping behaviors from broader domains.

Thirdly, it is recommended that cultural coping researchers routinely incorporate validated and established measures of culture (measures of collectivism-individualism, self-construals, acculturation, racial/cultural identity, etc.) in coping studies with culturally diverse samples. Inclusion of meaningful cultural constructs and measures would enable researchers to "unpackage" or explain how and what aspects of culture are contributing to the observed difference in behaviors (e.g., coping preferences) in a more concise manner (Smith \& Bond, 2003). As observed by Kuo (2011), this line of research goes beyond simply identifying between-group cultural difference in coping per se. It affords theoretically and empirically informed interpretations of why between-group variations in coping exist and what the implications are.

Finally, the present review focuses exclusively on the relationship between coping and collectivism - one of the four cultural dimensions according to Hofstede's (2001) formulation. It would extend the scope of existing cultural coping research to explore coping's link to Hofstede's other cultural dimensions, including power distance, uncertainty avoidance, and masculinity vs. femininity. For instance, previously discussed research on social context-dependent coping by Thai children (McCarty et al., 1999) and the identification of Respect for Authority Figures as a coping subscale in the Collectivistic Coping Scale (see Table 1; Yeh et al., 2003) have hinted at the possible association between coping preferences and power distance in these samples, rather than the sole influence of collectivism.

\section{CONCLUSION}

This narrative review is the first to comprehensively present evidence of collective coping and its implications for culturally diverse populations in North America and internationally. Continuous research efforts are needed to further refine and integrate theories, conceptualizations, and measurements of collective coping. To this end, researchers studying coping among culturally diverse participants should attend closely to the influences of collectivistic vs. individualistic values on the coping process and the etic versus emic cultural aspects of coping behaviors. By adopting culturally informed, multicultural perspectives on stress and coping, it is hoped that the field of coping research can ultimately move towards a more unified, crossculturally relevant stress-coping paradigm (Heppner, 2008; Wong \& Wong, 2006).

\author{
Manuscript received March 2011 \\ Revised manuscript accepted September 2011 \\ First published online February 2012
}

\section{REFERENCES}

Aldwin, C. M. (2007). Stress, coping, \& development: An integrative perspective (2nd ed.). New York, NY: Guilford Press.

Bhagat, R. S., Steverson, P. K., \& Kuo, B. C. H. (2009). Cultural variations in work stress and coping in an era of globalization. In R. S. Bhagat, \& R. M. Steers (Eds.), Handbook of culture, organizations, and work (pp. 418-441). Cambridge, UK: Cambridge University Press.

Chiang, L., Hunter, C. D., \& Yeh, C. J. (2004). Coping attitudes, sources, and practices among Black and Latino college students. Adolescence, 39, 793-815.

Chun, C. A., Moos, R. H., \& Cronkite, R. C. (2006). Culture: A fundamental context for the stress and coping paradigm. In P. T. P. Wong, \& L. C. J. Wong (Eds.), Handbook of multicultural perspectives on stress and coping (pp. 29-53). New York, NY: Springer.

Constantine, M. G., Donnelly, P. C., \& Myers, L. J. (2002). Collective self-esteem and Africultural coping styles in African American adolescents. Journal of Black Studies, 32, 698-710.

Constantine, M. G., Alleyne, V. L., Caldwell, L. D., McRae, M. B., \& Suzuki, M. B. (2005). Coping responses of Asian, Black, and Latino/Latina 
New York City residents following the September 11, 2001 terrorist attacks against the United States. Cultural Diversity \& Ethnic Minority, 11, 293-308.

Cross, S. E. (1995). Self-construals, coping, and stress in cross-cultural adaptation. Journal of Cross-Cultural Psychology, 26, 673-697.

Dunahoo, C., Hobfoll, S. E., Monnier, J., Hulsizer, M. R., \& Johnson, R. (1998). There's more than rugged individualism in coping: Part 1: Even the Lone Ranger had Tonto. Anxiety, Stress, and Coping, 11, 137-165.

Fischer, P., Ai, A. L., Aydin, N., Frey, D., \& Haslam, S. A. (2010). The relationship between regligious identity and preferred coping strategies: An examination of the relative importance of interpersonal and intrapersonal coping in Muslim and Christian faiths. Review of General Psychology, 14, 365-381.

Folkman, S., \& Moskowitz, J. T. (2004). Coping: Pitfalls and promise. Annual Review of Psychology, 55, 745-774.

Gaylord-Harden, N. K., \& Cunningham, J. A. (2009). The impact of racial discrimination and coping strategies on internalizing symptoms in African American youth. Journal of Youth \& Adolescence, $38,532-543$.

Heppner, P. P. (2008). Expanding the conceptualization and measurement of applied problem solving and coping: From stages to dimensions to the almost forgotten cultural context. American Psychologist, 68, 805-816.

Heppner, P. P., Heppner, M. J., Lee, D. G., Wang, Y. W., Park, H. J., \& Wang, L. F. (2006). Development and validation of a collectivist coping styles inventory. Journal of Counseling Psychology, $35,107-125$.

Hobfoll, S. E. (1998). Stress, culture, and community: The psychology and philosophy of stress. New York, NY: Plenum Press.

Hobfoll, S. E. (2001). The influence of culture, community, \& the nested-self in the stress process: Advancing conservation of resources theory. Applied Psychology, 50, 337-421.

Hofstede, G. (2001). Culture's consequences: Comparing values, behaviors, institutions, and organizations across nations (2nd ed.). Thousand Oaks, CA: Sage.

Horn, K. A. (2008). The relationship between acculturative stress, perceived discrimination, coping and multiculturalism in academic environments: A study among international students. Dissertation Abstracts International, 68(10-B).

Inman, A. G., \& Yeh, C. J. (2007). Asian American stress and coping. In F. T. L. Leong et al. (Eds.), Handbook of Asian American Psychology (2nd ed., pp. 323-340). Thousand Oaks, CA: Sage.

Joseph, J., \& Kuo, B. C. H. (2009). Black Canadians' coping responses to racial discrimination. Journal of Black Psychology, 35, 78-101.

Kim, H. S., Sherman, D. K., \& Taylor, S. E. (2008). Culture and social support. American Psychologist, 63, 518-526.

Kim, Y. H. (2009). Family role stressors, psychological distress, and marital adjustment in South Korean Families: Mediating role of collectivist coping strategies. ProQuest LLC: Dissertation and Theses, UMI No. 3381582.
Kuo, B. C. H. (2011). Culture's consequences on coping: Theories, evidence, and dimensionalities. Journal of Cross-Cultural Psychology, 42, 1082-1102.

Kuo, B. C. H., \& Gingrich, L. (2004). Correlates of selfconstruals among Asian and Caucasian undergraduates in Canada: Cultural patterns and implications for counseling. Guidance and Counseling, 20, 78-88.

Kuo, B. C. H., Roysircar, G., \& Newby-Clark, I. R. (2006). Development of the Cross-Cultural Coping Scale: Collective, avoidance, and engagement strategies. Measurement and Evaluation in Counseling and Development, 39, 161-181.

Lam, A. G., \& Zane, N. W. (2004). Ethnic differences in coping with interpersonal stressors: A test of selfconstruals as cultural mediators. Journal of CrossCultural Psychology, 35, 446-459.

Lazarus, R. S., \& Folkman, S. (1984). Stress, appraisal, and coping. New York, NY: Springer.

Lewis-Coles, M. E. L., \& Constantine, M. G. (2006). Race-related stress, africultural coping, and religious problem-solving among African Americans. Cultural Diversity \& Ethnic Identity, 12, 433-443.

Markus, H. R., \& Kitayama, S. (1991). Culture and the self: Implications for cognition, emotion, and motivation. Psychological Review, 98, 224-253.

McCarty, C. A., Weisz, J. R., Wanitromanee, K., Eastman, K. L., Suwanlert, S., Chaiyasit, W., et al. (1999). Culture, coping, and context: Primary and secondary control among Thai and American youth. Journal of Child Psychology and Psychiatry, 40, 809-818.

Moore, J. L., \& Constantine, M. G. (2005). Development and initial validation of the Collectivistic Coping Styles Measure with African, Asian, and Latin American international students. Journal of Mental Health Counseling, 27, 329-347.

Moos, R. H. (2002). 2001 invited address: The mystery of human context and coping: An unraveling of clues. American Journal of Community Psychology, 30, 67-88.

Neill, L. M., \& Proeve, M. J. (2000). Ethnicity, gender, self-esteem, and coping styles: A comparison of Australian and South-East Asian secondary school students. Australian Psychology, 35, 216-220.

Shek, D. T. L., \& Cheung, C. K. (1990). Locus of coping in a sample of Chinese working parents: Reliance on self or seeking help from others. Social Behavior \& Personality, 18, 327-346.

Sherman, D. K., Kim, H. S., \& Taylor, S. E. (2009). Culture and social support: Neural bases and biological impact. In J. Y. Chiao (Ed.), Cultural neuroscience: Cultural influences on brain function (Progress in brain research (Vol. 178, pp. 227-237). Amsterdam The Netherlands: Elsevier.

Smith, P. B., \& Bond, M. H. (2003). Honoring culture scientifically when doing social psychology. In $\mathbf{M}$. A. Hogg, \& J. Cooper (Eds.), Sage handbook of social psychology (pp. 43-61). London, UK: Sage.

Taylor, S. E., Welch, W. T., Kim, H. S., \& Sherman, D. K. (2007). Cultural differences in the impact of social support on psychological and biological stress responses. Psychological Science, 18, 831-837.

Triandis, H. C. (2001). Individualism-collectivism and personality. Journal of Personality, 69, 908-942.

Tweed, R. G., White, K., \& Lehman, D. R. (2004). Culture, stress, and coping: Internally- and externally-targeted control strategies of European 
Canadians, East Asian Canadians, and Japanese. Journal of Cross-Cultural Psychology, 35, 652-668.

Utsey, S. O., Adams, E. P., \& Bolden, M. (2000). Development and initial validation of the Africultural Coping Systems Inventory. Journal of Black Psychology, 26, 194-215.

Wei, M., Heppner, P. P., Ku, T. Y., \& Liao, K. Y. H. (2010). Racial discrimination stress, coping, and depressive symptoms among Asian Americans: A moderation analysis. Asian American Journal of Psychology, 2, 136-150.

Weisz, J. R., Rothbaum, F. M., \& Blackburn, T. C. (1984). Standing out and standing in: The psychology of control in America and Japan. American Psychologist, 39, 955-969.

Wester, S. R., Kuo, B. C. H., \& Vogel, D. L. (2006). Multicultural coping: Chinese-Canadian adolescents, male gender role conflict, and psychological distress. Psychology of Men and Masculinity, 7, 87-104.

Wong, P. T. P., \& Wong, L. C. J. (2006). Handbook of multicultural perspectives on stress and coping. New York, NY: Springer.

Yeh, C. J., Arora, A. K., \& Wu, K. A. (2006). A new theoretical model of collectivistic coping. In P. T. P. Wong, \& L. C. J. Wong (Eds.),
Handbook of multicultural perspectives on stress and coping (pp. 55-72). New York, NY: Springer.

Yeh, C. J., Chang, T., Kim, A. B., Arora, A. K., \& Xin, T. (2003, August). Reliability, validity, and factor analysis of the Collectivistic Coping Scale. Poster presented at the annual meeting of the American Psychological Association, Toronto, Canada.

Yeh, C. J., Inman, A. G., Kim, A. B., \& Okubo, Y. (2006). Asian American families' collectivistic coping strategies in response to 9/11. Cultural Diversity and Ethnic Minority Psychology, 12, 134-148.

Yeh, C. J., Inose, M., Kobori, A., \& Chang, T. (2001). Self and coping among college students in Japan. Journal of College Student Development, 42, 242-256.

Yeh, C. J., \& Wang, Y. W. (2000). Asian American coping attitudes, sources, and practices: Implications for indigenous counseling strategies. Journal of College Student Development, 41, 94-103.

Zhang, D., \& Long, B. C. (2006). A multicultural perspective on work-related stress: Development of a collective coping scale. In P. T. P. Wong, \& L. C. J. Wong (Eds.), Handbook of multicultural perspectives on stress and coping (pp. 555-576). New York, NY: Springer. 